\title{
Disorders of social functioning and quality of life in patients with gastroesophageal reflux disease while combined with undifferentiated connective tissue dysplasia
}

\author{
Iryna Romash \\ Ivano-Frankivsk National Medical University, Ukraine
}

\begin{abstract}
Introduction. It has been scientifically confirmed that the risk of developing gastroesophageal reflux disease (GERD) increases especially with generalized or regional disruption of connective tissue structure, which is widespread among the population. Patients with such comorbid pathology may have a wide range of symptoms that may go beyond the general symptoms of heartburn and regurgitation. The symptoms and complications of GERD affect general health, daily and social functioning, physical and emotional activity. It also affects the quality of life (QoL) associated with health through frequent breaks during sleep, work and social activities.

Purpose. study the dynamics of the level of quality of life and social functioning in patients with gastroesophageal reflux disease in combination with the syndrome of undifferentiated connective tissue dysplasia.

Methodology. A total of 120 patients were included in the study: 65 men and 55 women: in 75 of them (Group II) GERD occurred on the background of UCTD, in 45 (Group I) as an independent disease. The control group consisted of 12 healthy individuals. The study was comprehensive. The Medical Outcomes Study 36-ltem Short-Form Health Status (SF-36), the Gastrointestinal Symptom Rating Scale (GSRS) and the scale of "Personal and social performance" (PSP) - were used to study patients in detail.

Results and Discussion. Analyzing the results obtained on the basis of the GSRS questionnaire (Table 1), in patients with GERD on the background of UCTD, compared with patients of group I and the control group, there is a significant increase in three and four from the five scales. QoL in patients of Group II on the scale "Abdominal pain" were $14.3 \pm 0.4$ points, in Group I - $5.6 \pm$ 1.3 points, in the Control Group - $2.4 \pm 0.8$ points, on the scale "Reflux syndrome": $13.7 \pm 0.9$, $10.5 \pm 1.3$ and $3.1 \pm 0.9$, respectively. "Dyspeptic syndrome" - $15.3 \pm 0.4$ points in Group II, $12.2 \pm 0.6$ - in Group I and 6.1 \pm 0.3- in the control group. "Constipation syndrome" $9.5 \pm 0.8$, $5.6 \pm 1.03$ and $5.7 \pm 0.4$, respectively $(p<0,05)$.
\end{abstract}

Conclusions: In this research we investigated the effect of comorbid pathology on QoL in patients with GERD, which developed against the background of UCTD. The results confirm that patients with such combined pathology have a lower level of quality of life and social functioning, and the tactics of treatment of such patients should take into account these changes.

Keywords

Gastroesophageal reflux disease, undifferentiated connective tissue dysplasia, quality of life, social functioning.

Address for correspondence:

Iryna Romash, Department Propaedeutics of Internal Medicine, Ivano-Frankivsk National

Medical University, Ukraine. e-mail: iromash@ifnmu.edu.ua

This work is licensed under a Creative Commons Attribution-

NonCommercial 4.0 International License (CC BY-NC 4.0).

(c) (1) (3)

(c) Copyright: Romash, 2020

Licensee NDSAN (MFC- Coordinator of the NDSAN), Italy

DOI http://doi.org/10.32437/mhgci.v3i1.100

Submitted for publication: 21 July 2020

Received: 21 July 2020

Accepted for publication: 06 November 2020 


\section{Introduction}

The number of patients suffering from undifferentiated connective tissue dysplasia (UCTD) has been steadily increasing in recent decades and ranges from 9 to $85 \%$, depending on the population. As a premorbid background for the development of many pathological conditions and chronic diseases, the syndrome of UCTD requires more attention from clinicians. Especially often, against the background of this syndrome, there are disorders of the digestive system, in particular - the esophagus. The reason is the mesenchymal nature of its origin. Against the background of inflammatory diseases of the upper gastrointestinal tract more often than in patients without signs of dysplasia, motor dysfunction, in particular, gastro-oesophageal and duodeno-gastric reflux .

It has been scientifically confirmed that the risk of developing gastroesophageal reflux disease (GERD) increases especially with generalized or regional disruption of connective tissue structure, which is widespread among the population. Patients with such comorbid pathology may have a wide range of symptoms that may go beyond the general symptoms of heartburn and regurgitation (Kumar, A. et.al., 2020). The prevalence of GERD ranges from $5.2-8.5 \%$ in East Asia to $6.3-18.3 \%$ in Iran. And Arshad Kamal Butt et.al. in their study among Pakistanis note a much higher prevalence $-22.2 \%-24.0 \%$. There is a worldwide increase in the incidence of GERD and its complications, including Barrett's esophagus and esophageal adenocarcinoma. Back in 2008, GERD was classified as one of the 5 diseases, which significantly impairs the quality of life of patients. Recent studies by Michele Ludici on the quality of life (QOL) of patients with UCTD once again drew our attention to the comorbidity of these two conditions. This is because according to J. B. Marshall, most often in diseases of the connective tissue affect the esophagus. And V. Kondoh et. al. diagnosed with pathological reflux in $29.0 \%$ of patients with UCTD, while in its absence it was registered in $2.0 \%$ of those examined with GERD. Even more often manifestations of the gastroesophageal system were detected against the background of connective tissue pathology, which included its undifferentiated dysplasia, among which gastroesophageal reflux (GER) was observed in $68.0 \%$, regurgitation - in $43.0 \%$, dysphagia - in $33.0 \%$ of patients. Also, in UCTD, the balance between the factors of aggression and protection of the esophageal mucosa is disturbed by weakening the latter. According to the results of lower esophageal manometry, in $55 \%$ of patients with connective tissue pathology, there was a decrease in the tone of the lower esophageal sphincter, a symptom of which may be reflux (Denaxas et.al., 2018).

The symptoms and complications of GERD affect general health, such as daily and social functioning, physical and emotional activity. It also affects the quality of life associated with health through frequent breaks during sleep, work and social activities (ludici, M. et.al., 2017; Kumar, A. et.al., 2020).

These data are comparable with our previous data, according to which in adults with developed GERD on the background of UCTD, arthralgia, Raynaud's phenomenon, low body weight, bone, joint and skin phenotypic traits that correlate with the frequency and duration of GER. (Romash I.B et.al., 2020).

QoL research is a highly informative tool that determines the effectiveness of the health care system and allows to give an objective assessment of the quality of health care at the level of its main consumer - the patient. From the point of view of the principles of evidence-based medicine, the patient's QoL is the only noteworthy criterion and the main goal of the effectiveness of treatment of long-term, chronic diseases. (Romash I.R et. al., 2019; Moskalenko V. F et.al., 2014).

\section{Purpose}

The aim of the study was to study the dynamics of the level of quality of life and social functioning in patients with gastroesophageal reflux disease in combination with the syndrome of undifferentiated connective tissue dysplasia.

\section{Methodology}

From June 2017 to December 2019, 378 patients with GERD were examined in the University Clinic of Ivano-Frankivsk National Medical University and in the therapeutic department № 2 of the municipal enterprise "Central City Clinical Hospital" of Ivano-Frankivsk. The study included 134 patients. All of them provided written informed consent. During the study, 9 patients were lost for follow-up (at one stage or another expressed a desire not to continue to participate in the study).

During follow-up, 5 patients were diagnosed with certain differentiated connective tissue disease (1-scleroderma, 3-systemic lupus erythematosus and 1 Sjogren's syndrome), which 
were excluded from the study. 120 patients were included in the study: 65 men and 55 women: in 75 of them (group II) GERD occurred on the background of UCTD, in 45 (group I) as an independent disease. The control group consisted of 12 healthy individuals, without signs of UCTD, randomized by age and sex. The mean age of the subjects was $42.0 \pm 6.5$ years. The majority of patients (62\%) received higher and secondary special education, $75 \%$ of those surveyed were employed, and $7.3 \%$ retired.

When entering the study, the most common clinical manifestations were arthralgia / arthritis (45.6\%), Raynaud's phenomenon (45.6\%), dry eyes and/or mouth (32.6\%), frequent gastroesophageal reflux disease (32.6\%), myalgia (26.0\%) and asthenia (26.0\%).

The study was comprehensive. The Medical Outcomes Study 36-Item Short-Form Health Status (SF-36) (Ware et al., 1993), the Gastrointestinal Symptom Rating Scale and PSP - the scale of "Personal and social performance " (Morosini P. L., Magliano L., Brambilla L., Ugolini S., Pioli R., 2000) were used to study patients in detail.

Each patient was asked to complete a questionnaire SF-36.10, consisting of 36 questions grouped into 8 domains: physical functioning (PF), social functioning (SF), role limitations related to physical problems (RP), role limitations associated with emotional problems (RE), mental health (MH), vitality (VT), body pain (VP) and perception of general health $(\mathrm{GH})$. The indicators of each scale are compiled in such a way that the higher the value of the indicator (from 0 to 100), the better the score on the selected scale. From them form two parameters that estimate eight concepts of health: psychological and physical components. The physical component includes: $\mathrm{GH}$ - the general perception of health, PF - limitations in physical activity due to health problems, RP - limitations in normal role activities due to physical health problems, BP - physical pain. The mental component includes: SF limitations in social activities due to physical or emotional problems, $\mathrm{MH}$ - general mental health, psychological distress and well-being, RE limitations in normal role activities due to emotional problems, VT - viability (energy and fatigue). The scores of each scale vary between 0 and 100, where 100 represents complete health, and the results are presented as scores compiled in such a way that the higher score indicates a higher QoL level. This questionnaire is general, can be used for patients with various pathologies, as well as for population studies. It has proven itself in many clinical studies, easy to use.The questionnaire SF-36 is multidimensional, fairly simple, short, reliable, valid and sensitive.
Peculiarities of social dysfunction were assessed on the basis of the Personal and social performance (PSP) scale, which assesses the degree of impairment in four main areas: (a) socially useful activities, including work and study; (b) personal and social relationships; (c) selfservice; (d) restless and anxious behavior. The level of dysfunction was assessed by the severity of these areas from 0 to 5 (absent, weakly expressed, markedly expressed, significantly expressed, strongly expressed).

GSRS is a specific questionnaire consisting of 15 questions grouped into five clusters for a detailed study of symptoms reflecting reflux, abdominal pain, indigestion, diarrhea and constipation. GSRS has a seven-point Likert-type scale, where 1 means no problem symptoms and 7 means very problematic symptoms.

The reliability and validity of GSRS are well documented (Dimenäs, E et.al., 2008), and the values of the norms are available for the general population. In working with patients, we adhered to the ethical principles of the Declaration of Helsinki of the World Medical Association (Helsinki 1964, 2000 ed.). The study was approved by the Bioethics Committee of Ivano-Frankivsk National Medical University. Before inclusion in the study, all patients signed voluntary informed consent. All patients agreed to participate in the study and provided written informed consent

Statistical analysis of the results was performed using software packages STATISTICA 7.0., And a package of statistical functions of the program "Microsoft Excel, 2016". The reliability of the obtained indicators was confirmed by calculating errors for relative values, and the probability of data difference in the compared groups was proved based on calculating the coefficient $\dagger$ (Student) and determining the accuracy of the error forecast. The arithmetic mean (M), standard error $( \pm m)$ were used to describe quantitative features.

\section{Results and Discussion}

In the study and comparison groups, the analysis of QoL parameters was performed. The comparative analysis revealed a probable decrease in QoL in patients with GERD, which occurred against the background of connective tissue dysplasia. compared with the control group who did not have concomitant pathology.

When assessing the social functioning of patients with GERD comorbid with UCTD on the PSP scale, the most pronounced violations were found in the module "restless, anxious behavior" on average in Group I - $4.8 \pm 0.18$ points $(95 \% \mathrm{Cl}$ 4.6-4.9); Group II - $4.1 \pm 0.37$ (95\% Cl 3.73-4.47); 
Control Group - $4.9 \pm 0.1$ (95\% Cl 4.79-5.0). The cluster "personal and social relations" is presented as follows: $4.2 \pm 0.46$ points $(95 \% \mathrm{Cl}$ from 4.2 to $4.78) ; 3.2 \pm 0.18$ (95\% Cl 3.15-3.92), $4.8 \pm 0.16$ $(95 \% \mathrm{Cl} 4.53-5.0)$, respectively. The module "socially useful activity" and "self-service" was less affected, where group differences were not statistically significant.

Analyzing the results obtained based on the GSRS questionnaire (Table 1), in patients with GERD on the background of UCTD, compared with patients of group I and the control group, there is a significant increase in three and four of the five scales. QoL in patients of group II on the scale "Abdominal pain" was $14.3 \pm 0.4$ points, in group I - $5.6 \pm 1.3$ points, in the control group $2.4 \pm 0.8$ points, on the scale "Reflux syndrome": $13.7 \pm 0.9, \quad 10.5 \pm 1.3$ and $3.1 \pm 0.9$, respectively; "Dyspeptic syndrome" - $15.3 \pm 0.4$ points in the main (II) group $12.2 \pm 0.6$ - in the comparison group and $6.1 \pm 0.3$ - in the control group;"Constipation syndrome" $9.5 \pm 0.8,5.6 \pm$ 1.03 and $5.7 \pm 0.4$, respectively $(p<0,05)$.
In the study and comparison groups, the analysis of quality of life indicators was performed. The comparative analysis revealed a probable decrease in $Q \mathrm{OL}$, both among its physical and mental components, in patients of group II in comparison with group I who did not have concomitant pathology and control group. A comparative assessment of the dynamics of the physical components of the quality of life of patients with GERD against the background of NDST is presented in Figures $1 \mathrm{a}$ ) and 1b).

Table 1. Assessment of the quality of life in patients with GERD in combination with UCTD and as an independent disease.

\begin{tabular}{|l|l|l|l|l|l|l|}
\hline Clinical group & $\mathrm{n}$ & \multicolumn{3}{|l|}{ Quality of life according to the GSRS questionnaire, points } \\
\cline { 3 - 7 } & & $\begin{array}{l}\text { abdominal } \\
\text { pain }\end{array}$ & $\begin{array}{l}\text { reflux } \\
\text { syndrome }\end{array}$ & $\begin{array}{l}\text { diarrhea } \\
\text { syndrome }\end{array}$ & $\begin{array}{l}\text { dyspeptic } \\
\text { syndrome }\end{array}$ & $\begin{array}{l}\text { constipatio } \\
\mathrm{n} \\
\text { syndrome }\end{array}$ \\
\hline I Group (GERD) & 45 & $5.6 \pm 1.3^{*}$ & $10.5 \pm 1.3^{*}$ & $4.8 \pm 0.7$ & $12.2 \pm 0.6^{*}$ & $5.6 \pm 1.03$ \\
\hline $\begin{array}{l}\text { II Group } \\
\text { (GERD+UCTD) }\end{array}$ & 75 & $14.3 \pm 0.4^{* \wedge}$ & $13.7 \pm 0.9^{* \wedge}$ & $5.1 \pm 1.08$ & $15.3 \pm 0.4^{* \wedge}$ & $9.5 \pm 0.8^{* \wedge}$ \\
\hline Control Group & 12 & $2.8 \pm 0.4$ & $3.1 \pm 0.9$ & $3.4 \pm 1.07$ & $6.1 \pm 0.3$ & $5.7 \pm 0.4$ \\
\hline p1 (II Gr / I Gr.) & & $<0.01$ & $<0.01$ & 0.81 & $<0.01$ & $<0.01$ \\
\hline p2 (II Gr./Contr. Gr) & $<0.05$ & $<0.05$ & 0.26 & $<0.01$ & $<0.01$ \\
\hline
\end{tabular}

Notes:

1. ^ - $(p<0,05)$ data are reliable between the study groups.

2. ${ }_{-}(p<0,05)$ data are reliable relative to the control group. 


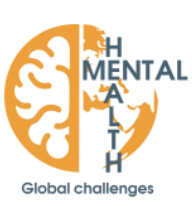

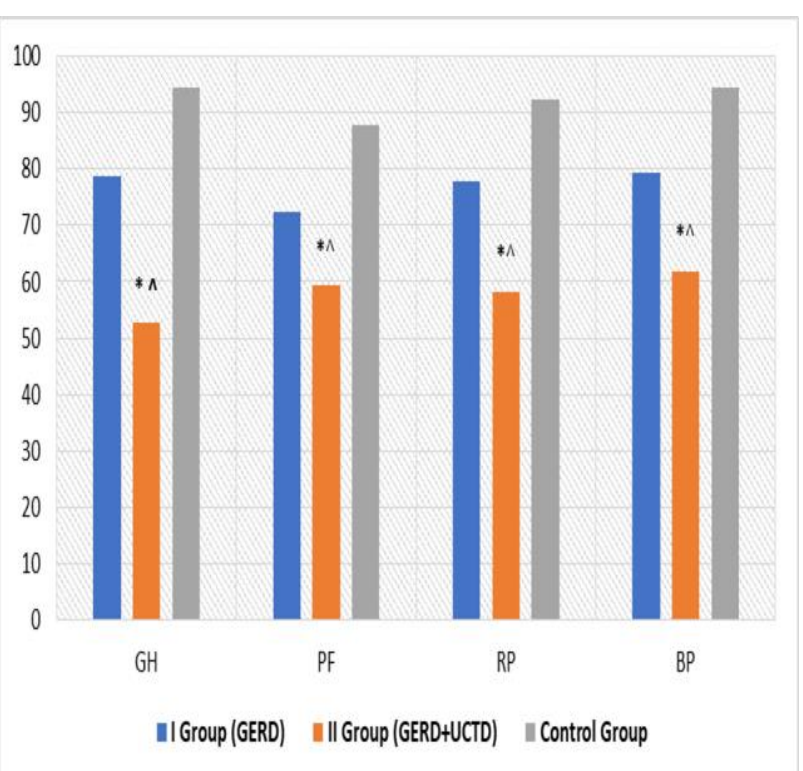

Fig. 1a) Dynamics of quality of life indicators (physical component of health) in patients with GERD.

\section{Notes:}

1. $\wedge$ - $(p<0,05)$ data are reliable between the study groups.

2 . * $(p<0,05)$ data are reliable relative to the control group.

\section{Conclusion}

In this research we investigated the effect of comorbid pathology on $\mathrm{QOL}$ in patients with GERD, which developed against the background of UCTD. The results confirm that patients with such combined pathology have a lower level of quality of life and social functioning, and the tactics of treatment of such patients should take into account these changes.

\section{Conflict of interest}

The author declares that she has no conflict of interests.

\section{References}

Denaxas K., Ladas S. D., Karamanolis G. P.(2018).

Evaluation and management of esophageal manifestations in systemic sclerosis. Ann Gastroenterol. 31(2):165-170. doi:10.20524/aog.2018.0228.

Dimenäs, E., Carlsson, G., Glise, H., Israelsson, B., \& Wiklund, I. (1996). Relevance of norm values as part of the documentation of quality of life instruments for use in upper gastrointestinal disease. Scandinavian Journal of Gastroenterology, 31(sup221), 8-13.

Iudici, M., Irace, R., Riccardi, A., Cuomo, G., Vettori, S., \& Valentini, G. (2017). Longitudinal

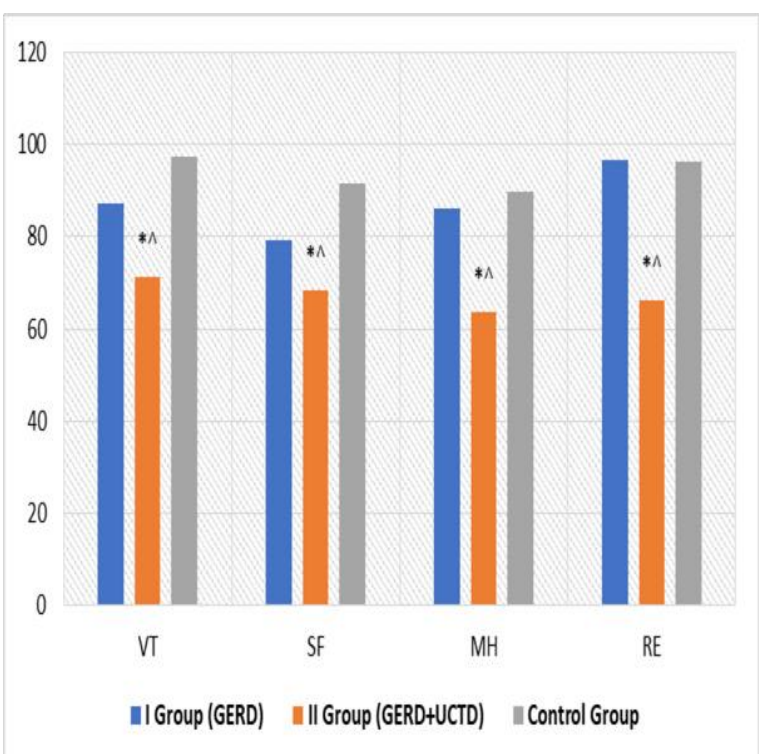

Fig 1b) Dynamics of quality of life indicators (mental component of health) in patients with GERD.

Notes:

1. $\wedge$ - $(p<0,05)$ data are reliable between the study groups. 2. * $(p<0,05)$ data are reliable relative to the control group.

analysis of quality of life in patients with undifferentiated connective tissue diseases. Patient related outcome measures, 8, 7.

Kulich, K. R., Madisch, A., Pacini, F., Piqué, J. M., Regula, J., Van Rensburg, C. J., Ujszászy, L., Carlsson, J., Halling, K., \& Wiklund, I. K. (2008). Reliability and validity of the Gastrointestinal Symptom Rating Scale (GSRS) and Quality of Life in Reflux and Dyspepsia (QOLRAD) questionnaire in dyspepsia: a six-country study. Health and quality of life outcomes, 6 , 12. https://doi. org/10.1 186/1477-7525-6-12

Kumar, A., Raja, K., Kumar, S., Quasimuddin, N. \& Rizwan, A. (2020). Quality of Life in Gastroesophageal Reflux Disease Three Months After Laparoscopic Nissen's Fundoplication. Cureus. Cureus. doi:10.7759/cureus. 10674

Moskalenko V. F., Bulakh I. Ye., Puzanova O. H. (2014). Metodolohiia dokazovoi medytsyny: pidruchnyk . Kyiv: «Medytsyna», 200 s.

Romash, I. B., \& Mishchuk, V. G. (2020). The frequency of visceral and phenotypic markers in patients with the combination of undifferentiated connective tissue disease and gastroesophageal reflux disease. Wiadomości Lekarskie, 73(7), 14921498.

Romash I.R., Vynnyk M.I. (2019) Dynamics of Quality of Life Indices in Case of Metabolic 
Syndrome in Patients with Paranoid Schizophrenia on the Background of Atypical Neuroleptic Agents Application and Improvement of Comorbidity. Ukrains'kyi visnyk psykhonevrolohii. 27,4 (101):62-67. DOl: https://doi.org/10.36927/2079-0325-V27-is42019-11 